\title{
Disinhibited Revenge - An fNIRS Study on Forgiveness and Cognitive Control
}

\author{
Moritz Julian Maier ${ }^{1,2}$, David Rosenbaum ${ }^{1}$, Florian Benedikt Haeussinger ${ }^{1}$, Martin Brüne ${ }^{3}$, \\ Andreas Jochen Fallgatter ${ }^{1,4,5}$ and Ann-Christine Ehlis ${ }^{1,4 *}$
}

'Psychophysiology and Optical Imaging, Department of Psychiatry and Psychotherapy, University of Tuebingen, Tuebingen, Germany, ${ }^{2}$ Graduate School of Neural and Behavioral Sciences, University of Tuebingen, Tuebingen, Germany, ${ }^{3}$ Department of Psychiatry, Psychotherapy and Preventive Medicine, Division of Cognitive Neuropsychiatry and Psychiatric Preventive Medicine, LWL University Hospital Bochum, Ruhr-University Bochum, Bochum, Germany, , ${ }^{4}$ LEAD Graduate School \& Research Network, University of Tuebingen, Tuebingen, Germany, ${ }^{5}$ Werner Reichardt Centre for Integrative Neuroscience (C/N), Tuebingen, Germany

The ability to reconcile is a key factor for a cooperative and successful life. Among the many factors that have an impact on how people negotiate social contracts, poor cognitive control (which is inversely linked to impulsivity) may exert negative effects on forgiveness. To investigate the neurobiological basis of this proposition, subjects with high vs. low impulsivity scores completed an ultimatum game (UG) and a dictator game (DG). First, the participants played an UG where they had to accept or reject offers from fair or unfair opponents. Afterward, the roles changed, and a DG was played. Here, subjects had the opportunity to forgive or take revenge on unfair opponents by the allocation of a fair/unfair amount of money. During this task, activity of the dorsolateral prefrontal cortex (DLPFC) was assessed via functional near-infrared spectroscopy (fNIRS). Highly impulsive subjects were significantly more revenge-seeking than individuals with a low impulsivity. This behavioral difference was reflected in the activation pattern of the left DLPFC, where higher activation in trials with unfair opponents was found, but only in the highly impulsive group. This result is discussed as an indicator of more revenge-driven behavior in highly impulsive individuals, since activity in the left DLPFC is associated with retaliation.

Keywords: cognitive control, forgiveness, fNIRS, revenge, impulsivity, dictator game, inhibition, emotion regulation

\section{INTRODUCTION}

"The weak can never forgive. Forgiveness is an attribute of the strong."

Gandhi

Stability of social relations, academic success, potential conflicts with the law-all of these highly relevant factors for a desirable life are strongly correlated with the concept of cognitive control (e.g., Nota et al., 2004; Moffitt et al., 2011; Inzlicht et al., 2015). While persons with high cognitive control are successful in various areas of life, a lack of cognitive control is often associated with poor psychosocial functioning. Several neuropsychiatric disorders such as attention deficit hyperactivity disorder (ADHD; e.g., Barth et al., 2015), drug dependence (e.g., Verdejo-Garcia et al., 2005; Barth et al., 2015) 
or Borderline Personality Disorder (Brüne et al., 2013) frequently display low states of cognitive control. Moreover, rumination-which is strongly connected to depression-is associated with a lack of cognitive control (Rosenbaum et al., 2017, 2018c), while conversely, therapeutic approaches to reduce rumination aim at improving cognitive control (Rosenbaum et al., 2018b). Cognitive control mainly consists of three neuropsychological subfunctions; updating, shifting, and inhibition (Miyake et al., 2000). Accordingly, updating can be seen as the persistent monitoring and task-based removal/adding of relevant content, while shifting describes flexible moving between different tasks or mental states; inhibition is defined as the suppression of prepotent (but not goal-oriented) response tendencies (Miyake and Friedman, 2012). Generally, cognitive control is negatively correlated with impulsivity (e.g., Bari and Robbins, 2013).

Cognitive control plays a central role in the negotiation of social contracts of all kinds, including deception and reconciliation (Karremans and van der Wal, 2013). The importance of successful forgiveness, for example, is underlined by associations with general health outcomes [and especially cardiovascular health (Friedberg et al., 2007)], stress perception (Worthington et al., 2007) and overall mortality (Toussaint et al., 2012). Forgiveness can be described as a fluent process which consists of two steps; first, the decision to forgive the provocateur, and second, the inhibition of revenge-seeking feelings (Fincham et al., 2006; Wilkowski et al., 2010). These feelings, like anger and hate, are a natural reflexive response to transgressions, according to Pingleton (1989). Therefore, inhibition in particular (as a subfunction of cognitive control) is discussed as a key factor in successful reconciliation. Neurobiologically, the conflict monitoring theory (Botvinick et al., 2001), posits that potential response conflicts (e.g., the decision to forgive vs. the impulsive desire for revenge) are associated with the activation of the anterior cingulate cortex (ACC), which signals an increased need for the implementation of cognitive control to the dorsolateral prefrontal cortex (DLPFC; e.g., Kerns et al., 2004; Egner and Hirsch, 2005). According to this conceptual embedding, differences between high- and low forgiving individuals should be visible, especially in the DLPFC.

However, it should be noted that besides the DLPFC, other brain areas are also involved in forgiveness. For example, Ricciardi et al. (2013) found significant covariations between the ACC, the DLPFC and the inferior frontal gyrus (IFG) during forgiveness processes. According to the authors, the ACC is associated with affective and emotional processing in forgiveness (Bush et al., 2000), while the IFG is associated with cognitive and emotional empathy (Shamay-Tsoory et al., 2009). Although other brain regions are important for a complex cognitive process such as forgiveness, the DLPFC has been selected as the area of interest in this study, as it is thought that this brain region controls areas such as the IFG and ACC during forgiveness processes (Clark, 2005).

To study the neurobiological basis of revenge and forgiveness, Brüne et al. (2013) developed a study design, which enabled participants to forgive unfair opponents or to take revenge in a controllable experimental setting. To this end, the participants first played an ultimatum game (UG) where a virtual opponent split up 10 Euro on each trial and the participants had to accept or reject the offer. During the game, the participants learned implicitly that half of the opponents were fair (offers between 3 and 5 Euro) and the other half were unfair (offers between 0 and 2 Euro). Subsequently, the roles changed, and the subjects had to split up 10 Euro between themselves and the previous opponents in a dictator game (DG). Here, subjects had the possibility to forgive their previously unfair opponents or to take revenge. The slight difference between the UG and the DG, when considering the rejection possibilities is important to note: since the opponents had no possibility to reject an offer made by the participants in the DG, the subjects were able to allocate the money without any fear of rejection. In their study, Brüne et al. (2013) found a significantly higher activation of the right DLPFC when subjects "forgave" their previously unfair opponents (by allocating a fair amount of money themselves) in comparison to allocating a fair amount of money to a previously fair opponent. This result can be interpreted as an indicator that forgiveness processes are (partly) controlled by the DLPFC and thus by a classical cognitive control region. To further assess the causality of this finding, Maier et al. (2018) combined the paradigm of Brüne et al. (2013) with an inhibitory continuous theta-burst stimulation (cTBS, Huang et al., 2005) in order to test the effects of reduced activity in the right DLPFC in forgiveness behavior. In this study, reduced forgiveness (i.e., more revenge-seeking) behavior towards previously unfair opponents was found, after inhibition of the right DLPFC via the cTBS. The emotions experienced towards the opponents were the same in both conditions. Strong negative emotions towards unfair opponents and positive emotions towards fair opponents. Along similar lines, in a study, Müller-Leinß et al. (2018) found that when using repetitive transcranial magnetic stimulation (rTMS), inhibition of the right DLPFC not only led to an increased punishment of previously unfair opponents, but also to less fair behavior toward previously fair players, suggesting maximization of one's own monetary benefit in a "homo economicus"-like fashion.

To further investigate the connection between cognitive control and forgiveness behavior, the question arises how forgiveness behavior differs between subjects with high- vs. low cognitive control. If subjects with low cognitive control would act in a less forgiving manner, it would indicate that this subgroup fails in inhibiting revenge-seeking feelings. To clarify this potential correlation, we compared subjects with high vs. low cognitive control (as defined by low vs. high impulsivity scores) with the combination of an UG and a DG. To control the cognitive control abilities of the subjects in an objective and reliable way, an Emotional Stroop-task was used to assess both cognitive control and implicit emotions. In the EmotionalStroop task, color words of the classical Stroop-task are replaced with emotional vs. non-emotional words. Using this task, which was run after the UG and DG, it was possible to measure both the cognitive control and the implicit emotionality of the participants. Based on previous work using this paradigm (Brüne et al., 2013; Müller-Leinß et al., 2018; Maier et al., 2018) and the outlined theoretical considerations, we propose the following hypotheses: subjects with low cognitive control will allocate 
unfair amounts of money to unfair opponents more often than subjects with high cognitive control (i.e., more impulsive retaliation). We expect no differences between groups towards the fair opponents because the interaction lacks the provocation of revenge. These specific effects should be accompanied by activation differences in the right DLPFC: we expect significantly less activation in the right DLPFC in subjects with low cognitive control compared to subjects with high cognitive control. This difference between the groups should be particularly accentuated in trials where the subjects face previously unfair opponents, due to a high need for cognitive control in terms of the inhibition of revenge-seeking behavior.

\section{MATERIALS AND METHODS}

\section{Subjects}

Subjects with high- vs. low cognitive control were screened via online questionnaires to assess demographic data, potential exclusion criteria, and impulsivity scores using the impulsivity scale of the adult ADHD self-report scale (ASRS; Kessler et al., 2005). Exclusion criteria included chronic or acute diseases that can influence the cerebral metabolism (moderate or severe craniocerebral trauma, kidney insufficiency, diabetes and unattended hypertension) or acute endangerment of the self or others. Additionally, they were asked if they were at present or in the past under medical treatment because of neurological or psychiatric illness or if they took any (illegal) drugs the last month. In case of uncertainty regarding this question there was a free-text field where potential subjects were able to indicate potential problems. Subjects with scores between 15 and 23 on the ASRS were assigned to the high impulsivity group (=low cognitive control); subjects with scores lower than 10 were assigned to the low impulsivity group (=high cognitive control). These thresholds were already used in various previous studies (e.g., Herrmann et al., 2009) and provided clearly differentiable participant groups without recruiting a clinical group. This study was approved by the ethics committee of the Medical Faculty of the University of Tübingen, in accordance with the current version of the Declaration of Helsinki. Written informed consent was obtained from all participants.

In total, 67 subjects participated. Twenty-nine were assigned to the low impulsivity subject group, 38 to the highly impulsive subject group. The mean age was 34.4 years $(\mathrm{SD}=2.95)$, 50 participants were females, 17 males. Considering age and sex no significant differences were observed $\left(t_{(65)}=1.11, p=0.271\right.$; $\left.\chi^{2}=0.592, p=0.442\right)$.

\section{Experimental Process}

After arriving and signing the written informed consent form, the functional near-infrared spectroscopy (fNIRS) probeset was mounted and the experiment started with the UG, which was directly followed by the DG. Other tasks, which were part of a different study and are reported elsewhere, followed approximately $30 \mathrm{~min}$ after the DG. At the end, an Emotional Stroop task (Williams et al., 1996) was run to further assess cognitive control capacities as well as emotionality.

\section{Paradigm}

The paradigm was adapted from Brüne et al. (2013) and consisted of two subsequent tasks, an UG followed by a DG. Every game consisted of 40 trials in total and had a duration of approximately 9 min. First, an UG was played against four virtual opponents. During each trial, the opponent split up 10 Euro (virtual money, 10 trials per opponent, randomized order) between themselves and the subject. The participants had the choice to accept or to reject the offer. In case of a rejection, neither the subject nor the opponent received any money. Therefore, a rejection was also an option to punish unfair offers made by the opponents. During this task, the subjects implicitly learned that there are two fair (one male, one female; offers between 3 and 5 Euro) and two unfair opponents (offers between 0 and 2 Euro). The classification of fair and unfair offers was made based on previous studies (e.g., Sanfey et al., 2003; Brüne et al., 2013). Every trial began with the presentation of the name and face of the opponent for $3 \mathrm{~s}$, which was followed by a jittered 2-3 s anticipation period. After that, subjects were presented with the offer of the opponent for $3 \mathrm{~s}$. During this decision period, subjects had to indicate their response (acceptance vs. rejection) via a button press. After that, a feedback screen was presented for $3 \mathrm{~s}$. An inter-trial interval of jittered 2-3 s followed subsequently.

After the completion of the UG, a DG was played. Here, the roles changed, and the participants had to split up the money. The opponents (now the recipients) were the persons introduced in the previous UG. As in the UG, 40 trials- 10 per opponent-were played. An important difference in comparison to the previously played UG is that the opponents had no possibility to reject the offers made by the participants (which clearly reduces the fear of punishment for unfair money allocations). The timing and order were (beside the no choice circumstance) the same as in the UG. In both games, the participants had the instruction to imagine that they were playing for real money and with real persons (with the aim to increase the involvement of the participants). As we used computer opponents with pictures taken from the study of Brüne et al. (2013), the participants were not familiar with the four different characters of the game before the ultimatum- and DG. In both paradigms, the participants were seated in front of an Eizo ${ }^{\circledR} 22$-inch screen, at a distance of approximately $60 \mathrm{~cm}$. Only participants with normal or corrected visual capabilities were included.

\section{Emotional Stroop Task}

Cognitive control and affective state were measured with an Emotional Stroop task (Watts et al., 1986). Based on the stimuli of Smith and Waterman (2003), the task consisted of negative, positive and neutral words (10 stimuli per category). These 30 words were presented in four different colors (blue, green, red, yellow), resulting in 120 different stimuli, which were presented in the center of a black screen. The responses were assessed via a button box with one button per color. As a reminder, a buttoncolor-assignment was presented during the whole experiment. In the beginning, 20 training trials with a correct/incorrect feedback were run. Subsequently, the experiment started with a fixation cross for $200 \mathrm{~ms}$, followed by a target stimulus until 
response (timeout after 1,000 ms). In the experimental trials, no feedback was presented. Between the trials, a jittered break of 4,000-7,000 ms appeared (Plichta et al., 2007).

\section{fNIRS}

To assess cortical activation of the DLPFC during the DG, fNIRS was used. Biological tissue (e.g., skin or bones) is relatively transparent for near-infrared light, and oxygenated $\left(\mathrm{O}_{2} \mathrm{Hb}\right)$ and deoxygenated $(\mathrm{HHb})$ hemoglobin absorb near-infrared light with different absorption spectra (Fallgatter et al., 2004; Haeussinger et al., 2011). Due to these preconditions, it is possible to measure relative changes in $\mathrm{O}_{2} \mathrm{Hb}$ and $\mathrm{HHb}$ in the upper $2-3 \mathrm{~cm}$ of the cortex. Based on the principle of neurovascular coupling, a decrease of $\mathrm{HHb}$ and an increase in the concentration of $\mathrm{O}_{2} \mathrm{Hb}$ indicates cortical activation within a specific brain region. The measurements for this study were run using a commercial multichannel fNIRS system (ETG-4000 Optical Topography System; Hitachi Medical Company, Japan) with a temporal resolution of $10 \mathrm{~Hz}$. A $3 \times 11$ probeset with 52 channels (16 detectors, 17 emitters, and an interoptode at distance of $3 \mathrm{~cm}$ ) was oriented on a reference point $\mathrm{Fpz}$ and T3/T4 based on the international 10-20 system (Jasper, 1958).

\section{Questionnaires}

In addition to the questionnaires for the screening of suitable participants, forgiveness and cognitive control-related variables were assessed. These questionnaires were completed online via a Sosci Survey (Leiner, 2018) within 1 week before the measurement. The following questionnaires were used: the Beck Depression Inventory (BDI; Beck et al., 1996), the Tendency to Forgiveness Scale (Brown, 2003) and the Willingness to Forgive Scale (Allemand et al., 2008). After the experiment, the desire for revenge and sympathy perception (0-5, $0=$ low feelings of sympathy/revenge) of the participants towards their opponents was additionally assessed.

\section{Statistical Processing (Behavioral Data)}

The rejection rate in the UG between both groups was compared with an unpaired $t$-test. To test the hypothesis of an interaction effect of fairness of the opponent (fair vs. unfair) and group of the subject (high vs. low cognitive control), a non-parametrical permutation test was used for the analysis of money allocation during the DG, due to non-normally distributed data. First, using a permutation test for repeated measurements, the differences between the offers towards fair vs. unfair opponents were analyzed. Second, the difference between offers (towards fair opponents) and offers (towards fair opponents) was compared between the groups by a comparison of difference scores ( $\Delta$ fair Opponent - unfair Opponent) using the same test method (see e.g., Gibbons and Chakraborti, 2011). For all analyses, MATLAB 2015b (The MathWorks, Natick, MA, USA) or SPSS 22 (SPSS Inc., Chicago, IL, USA) were used.

\section{Statistical Processing (fNIRS Data)}

All fNIRS data were exported without any pre-processing. For all following analyses, MATLAB 2017 (The MathWorks, Natick, MA, USA) was used. All frequencies $<0.01 \mathrm{~Hz}$ and $>0.5 \mathrm{~Hz}$ were excluded with a bandpass filter. For the correction of motion artifacts, the correlation based signal improvement (cbsi) procedure of Cui et al. (2010) was used, and the resultant cbsi-hb was used for all subsequent analyses. Additionally, an Independent Component Analysis (ICA; Delorme and Makeig, 2004) was applied to exclude high amplitude artifacts. The left and the right DLPFC were defined as regions of interest (ROIs); the allocation of NIRS channels to these ROIs was made in accordance with Rorden and Brett (2000), Singh et al. (2005) and Tsuzuki et al. (2007). The positions of the ROIs are depicted in Figure 1. Afterward, the mean activation of the ROIs was extracted for further analyses. First, a $2 \times 2$ ANOVA with the within-subjects factor opponent (fair vs. unfair) and the betweensubjects factor group (highly impulsive vs. low impulsivity) was run, separately for each ROI. As post hoc tests, $t$-tests were used. For a better comparability, the fNIRS data was $z$ transformed. The factor of money allocation was not included because of different frequencies in the different conditions/groups. For example, the combination "unfair offer towards a previously fair opponent" was absent. Especially in the response to unfair opponents, the frequency of fair vs. unfair offers was so different between the groups that a comparison of the fNIRS data did not seem to make much sense. Additionally, with the combined analysis of all trials (independent of the exact money allocation),

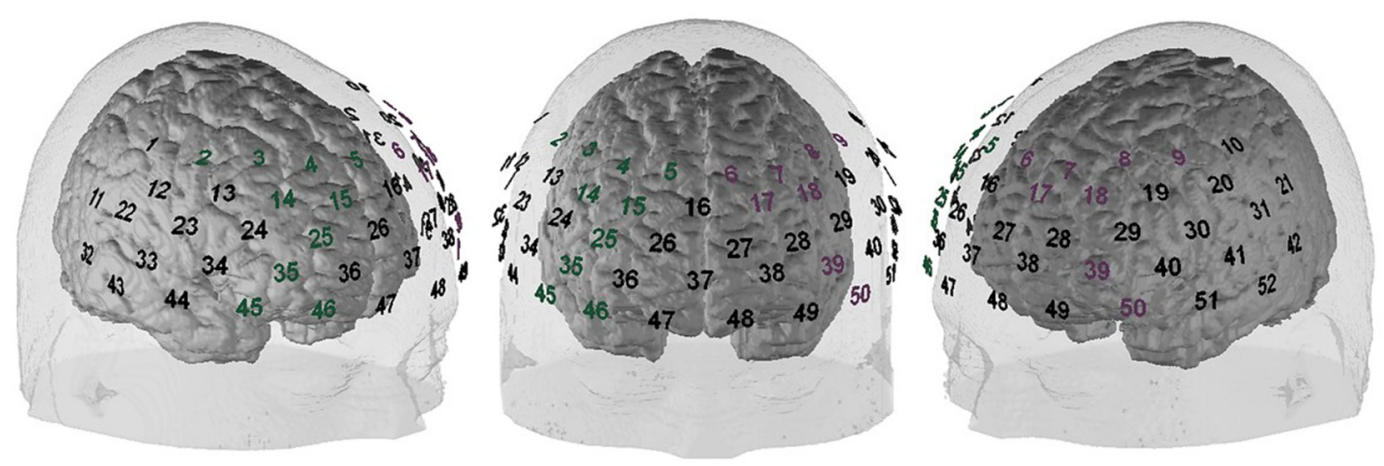

FIGURE 1 | Functional near-infrared spectroscopy (fNIRS) probeset position. Green numbers indicate the right dorsolateral prefrontal cortex (DLPFC), pink numbers indicate the left DLPFC 
statistical power was increased, and we were able to investigate the mechanisms underlying behavioral differences between the groups.

\section{Statistical Processing (Stroop Data)}

For analysis of the Stroop data, the inversed efficiency score (IES $=\frac{R T}{1-\text { Proportion of errors }}$; Townsend and Ashby, 1983) was used. Trials with differences of more than two standard deviations from the mean per person (in total 3.72\%) and incorrect trials were excluded from the analyses. After an ANOVA where no effect for stimulus valence was found, the data were merged for valence and the difference between the groups was assessed with a $t$-test for independent measurements.

\section{Statistical Processing (Correlations)}

To analyze potential brain-behavior correlations, the frequency of fair responses towards unfair opponents was calculated (=forgiveness behavior). Subsequently, this frequency was correlated (Pearson method) to the event related average (ERA) of the left DLPFC (referring to the fNIRS results) for the trials with fair and unfair opponents. The $\alpha$-value was adjusted for multiple tests using the Bonferroni method (Dunnett, 1955).

\section{Statistical Processing (Logistic Regression Analysis)}

To further analyze the results, a logistic regression separated for the groups (low vs. highly impulsive) was run. The dependent variable was the number of trials with fair offers [fair offers were defined as offer $\geq 3 €$ (see Brüne et al., 2013)] towards unfair opponents (=frequency of forgiveness); independent variables were the activation in the right and left DLPFC in trials with unfair opponents, the IES, the scores of the Tendency to Forgiveness Scale, and the Willingness to forgive Scale as well as the scores of revenge and sympathy feelings of participants towards unfair opponents.

\section{RESULTS}

\section{Stroop Task and DG Behavioral Results}

In line with our hypothesis, the highly impulsive subject group had a significantly higher IES score (indicative of lower cognitive control) than the low impulsivity subject group $\left(t_{(53)}=-2.53\right.$, $p=0.014 ; \mathrm{M}_{\text {highly impulsive }}=724.08$ vs. $\mathrm{M}_{\text {low impulsivity }}=650.89$ ).

The rejection rate in the UG did not significantly differ between the groups $\left(t_{(53)}=1.01, p=0.315\right)$. As expected, for behavior in the DG (mean amount of allocated money) towards previously fair opponents, no effect was found $[p>0.05$; Mean $_{\text {low_impulsive }}=4.08 €(S D=0.96)$, Mean highly_impulsive $=3.86$ $€(S D=0.99)]$. For unfair opponents, a significant difference between the groups was found $\left[p<0.05\right.$; Mean $_{\text {low impulsive }}=2.86$ $€(S D=1.21)$, Mean $\left._{\text {highly_impulsive }}=2.20 €(S D=1.24)\right]$. Permutation tests for the double contrast (highly impulsive vs. low impulsivity for fair vs. unfair opponents) further indicate a significant interaction between both factors [group $\times$ opponent; $p<0.05, \Delta_{\text {low_impulsivity (fair Opponent }- \text { unfair Opponent) }}=1.22 €$ $(S D=0.88)$ vs. $\Delta_{\text {highly_impulsive }}($ fair Opponent - unfair Opponent $)=1.65$
$€(S D=0.97)]$. Figure 2 depicts the probability density function estimate separately for the group and opponents.

\section{Questionnaire Results}

For the results of the questionnaires and group comparisons, see Table 1. In a $t$-test for unrelated measurements, a significantly higher mean BDI was found in the highly impulsive group. Additionally, a significantly higher desire for revenge on unfair opponents was found in this group. In the low impulsivity group a marginally higher feeling of sympathy was found. The difference of the sympathy and desire for revenge experienced towards fair vs. unfair opponents differed significantly for both groups (in each case $p<0.001$ ).

\section{fNIRS Results}

We ran a $2 \times 2$ ANOVA with the within-subjects factor opponent (fair vs. unfair) and the between-subjects factor group (highly impulsive vs. low impulsivity) separated for the left and the right DLPFC. We found no effect in the right DLPFC. In the left DLPFC, a main effect for opponent $\left(F_{(1,65)}=4.53, p=0.037\right)$ and an interaction effect of group and opponent was found $\left(F_{(1,65)}=4.28, p=0.042\right)$. Subsequently, a post hoc $t$-test for repeated measurements was run separately for groups. No significant differences between fair and unfair opponents occurred in the low-impulsivity group $\left(t_{(37)}=0.51\right.$, $p=0.960$ ). However, in highly-impulsive subjects, a significant difference between trials with fair vs. unfair opponents was found $\left(t_{(28)}=2.40, p=0.023\right)$, with higher hemodynamic responses in the left DLPFC during money allocation to unfair opponents. These effects are depicted in Figure 3.

\section{Correlational Results}

In the highly impulsive group, no significant correlations were found. In contrast, the low impulsivity group showed a significant negative correlation $(r=-0.499, p=0.018)$ between activation in the left DLPFC and the frequency of fair offers towards unfair opponents (=forgiveness behavior).

\section{Regression Analyses}

For the low impulsivity group, only the perceived sympathy of the unfair opponent had a significant influence on the response towards unfair opponents $\left(F_{(1,22)}=7.36, p=0.013, n=23\right)$. With one point more in the sympathy rating (sympathy feelings towards unfair opponents), the low impulsivity subjects allocated on average $1.068 €$ more to unfair opponents. For the highly impulsive subjects, only the perceived revenge feeling towards unfair opponents had a significant influence on their money allocation towards unfair opponents $\left(F_{(1,21)}=6.85, p=0.016\right.$, $n=22$ ). With one point more in the revenge rating (revenge feelings towards the unfair opponents), the highly impulsive subjects allocated on average $4.096 €$ less to unfair opponents.

\section{DISCUSSION}

This study investigated the effects of cognitive control mechanisms on forgiveness towards unfair opponents in a combined ultimatum/DG. The results of the Emotional Stroop task confirmed the expected lower cognitive control 


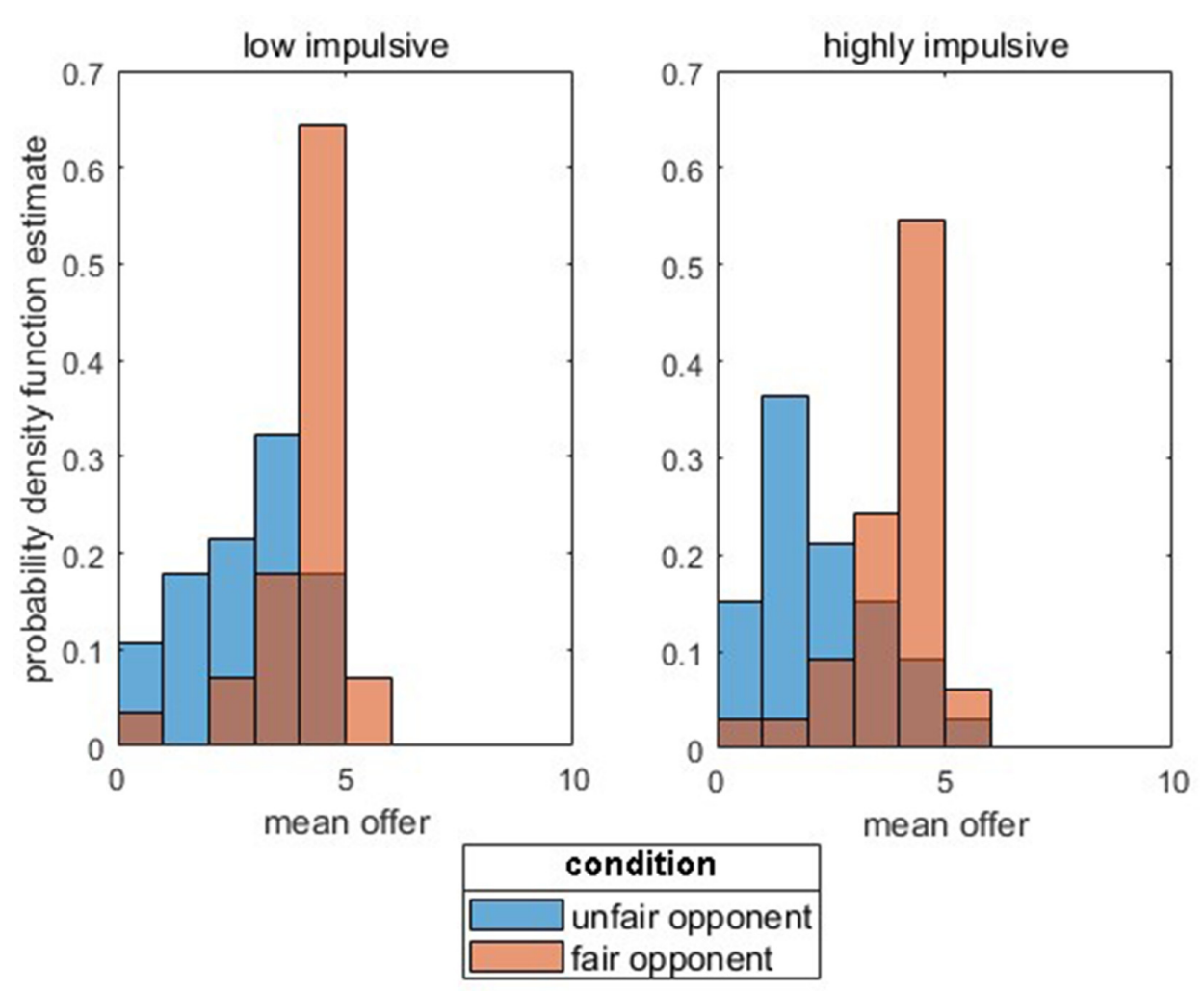

FIGURE 2 | Probability function estimate for low impulsivity vs. highly impulsive subjects for the mean offers (in €) separated for unfair (blue columns) vs. fair (orange columns) opponents.

capacity of the highly impulsive group. A significant difference between the groups was observed towards previously unfair opponents (where forgiveness is necessary for a fair response). As hypothesized, the highly impulsive group showed significantly less forgiveness/more revenge behavior. According to our hypotheses, we found no behavioral differences between groups towards previously fair opponents (control condition).

We also hypothesized that higher rates of forgiveness in the low impulsivity group would be accompanied with higher activity in the right DLPFC, comparable to other results in this field (e.g., Brüne et al., 2013; Maier et al., 2018). Surprisingly, we found no activation differences between fair and unfair opponents in the low impulsivity group and no group difference regarding the activation of the right DLPFC. In the left DLPFC, highly impulsive subjects exhibited significantly higher activation when playing against unfair opponents as compared to fair opponents. As it is assumed that cognitive control is needed to forgive (e.g., Pronk et al., 2010), and the left DLPFC is generally seen as a cognitive control region (e.g., Botvinick et al., 2001; Egner and Hirsch, 2005), this finding only in the highly impulsive group (which was less forgiving) is unexpected. To further analyze these unforeseen results, we ran a multiple regression analysis to explore the mechanisms underlying the different behavioral patterns in the low vs. highly impulsive group. While in subjects with low impulsivity only perceived sympathy for their virtual (unfair) opponents predicted money allocation, in the highly impulsive group revenge feelings significantly predicted the behavior. One explanation for the increased activation in the

TABLE 1 | Results of the different questionnaires separated by groups.

\begin{tabular}{|c|c|c|c|}
\hline Questionnaire & $\begin{array}{l}\text { Low impulsivity } \\
\text { group } \\
\text { (23 females, } \\
6 \text { males; } M, S D)\end{array}$ & $\begin{array}{c}\text { Highly impulsive } \\
\text { group } \\
\text { (27 females, } \\
11 \text { males; } M, S D \text { ) }\end{array}$ & $\begin{array}{c}t \text {-value, } p \text {-value } \\
\text { (one-tailed) }\end{array}$ \\
\hline $\mathrm{BDI}$ & $4.44,3.13$ & $9.60,7.07$ & $-4.00,<0.001^{*}$ \\
\hline Tendency to forgiveness Scale & $15.25,4.15$ & $14.48,4.67$ & $0.68,0.245$ \\
\hline Willingness to forgive Scale & $20.96,5.12$ & $21.21,5.04$ & $-0.19,0.423$ \\
\hline Desire for revenge (towards unfair opponents) & $2.67,0.99$ & $3.13,1.03$ & $-1.79,0.035^{*}$ \\
\hline Feelings of sympathy (towards unfair opponents) & $2.10,0.53$ & $1.90,0.59$ & $1.43,0.075$ \\
\hline
\end{tabular}

*Significant group difference $(p<0.05)$. 

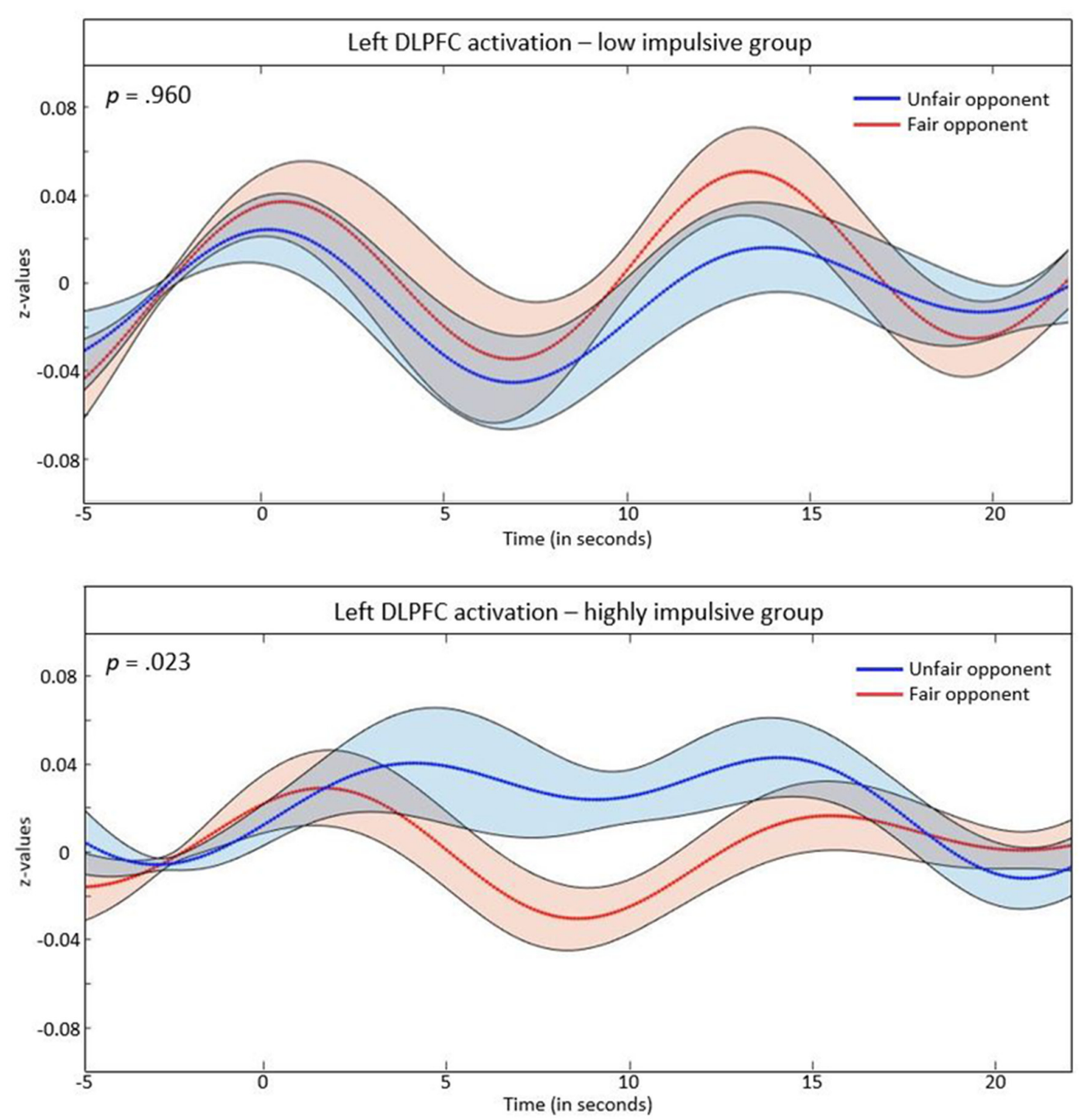

FIGURE $3 \mid z$-values of the event related average (ERA) signal in the left DLPFC separated for the low impulsivity and highly impulsive group. The shaded parts indicate the standard error of the mean.

left DLPFC in highly impulsive subjects during money allocation to unfair opponents, might therefore lie within this revenge motivation. In a study of Strobel et al. (2011), higher activation in the left DLPFC was observed during a DG with the option for punishment. In line with this, Ricciardi et al. (2013) found higher left DLPFC activation during revenge in comparison to forgiving during social scenario evaluations. The stronger revenge-driven behavior of the highly impulsive subject group lines up very well with the results of Jones and Paulhus (2011) who also found more pronounced psychopathy and narcissism scores in persons with high impulsivity scores.

The fact that the low impulsivity group unexpectedly did not show increased activation in cognitive control areas, despite displaying more pronounced forgiveness behavior, might be explained by the specificities of the low impulsivity control group. It is assumed that cognitive control is needed to forgive due to the necessary suppression of unwanted (e.g., revenge-seeking) emotional feelings (Wilkowski et al., 2010; Maier et al., 2018). James and Taylor (2007) found that impulsivity is positively correlated with negative emotionality. This aligns well with the significantly lower desire for revenge in the low impulsivity group also after unfair treatment, which may have led to a reduced need to suppress unwanted revenge-seeking feelings via mechanisms of cognitive control. To summarize, the unexpected lack of significant activation in cognitive control areas (i.e., DLPFC) in the low impulsivity group could be explained by the fact that these subjects did not have any unwanted emotions to suppress, whereas the highly impulsive subjects were primarily revenge-driven in their behavior. 
Alternatively, the unfair behavior of the highly impulsive group could also be interpreted as a more controlled and economically elaborated behavior, since allocating a small ("unfair") amount of money makes sense from an economical perspective (e.g., Fehr and Fischbacher, 2004), depending on one's motivational attitude. The higher activation in the left DLPFC as part of the cognitive control network could reflect this elaborated and cognitively controlled behavior. However, this interpretation would be contradictory to the results of the Emotional Stroop task and previous findings on the connection between impulsivity and (low) cognitive control (e.g., Fallgatter et al., 2005; Ehlis et al., 2008; Herrmann et al., 2010) and is therefore rather implausible.

Attention should also be given to the fact that the highly impulsive group indicated significantly higher values in the BDI. All subjects were far away from a pathological threshold (only subjects without psychiatric disorders were invited), nevertheless in the literature depression is linked with lower abilities to forgive (Tse and Cheng, 2006; Hirsch et al., 2011). But keeping the ecological validity in mind and the strong connection between the concepts of impulsivity and depression, an avoidance of these differences would not be useful. Furthermore, attention should be given for a potential influence of impulsivity on the behavior in the UG. In the present study, this was not the case but in other previous studies, the possibility of an influence was shown (see Crockett et al., 2010; Espín et al., 2015).

In future studies other brain regions like the posterior parietal cortex should also be studied, as this brain region, in combination with the DLPFC, is known to be part of the central executive network (Sridharan et al., 2008; Rosenbaum et al., 2018a). This network is inter alia responsible for social cognition which plays a crucial role in forgiveness processes (Sherman et al., 2014). More knowledge about the underlying network mechanisms would help in understanding the neural foundations of forgiveness processes to a new extent. Furthermore, other brain areas like the ACC and the IFG, which are known to play a role in forgiveness processes, could be investigated for their role in prosocial behavior in future studies. The highly significant differences in the sympathy and desire for revenge experienced towards fair vs. unfair opponents indicate that the manipulation used in the present study worked as planned. Nevertheless, in future studies a design in which participants are playing against real opponents while receiving a financial compensation based on their behavior during the game, could increase the personal involvement of the participants and could strongly influence the results, especially as there are previous works showing that there are differences in behavior between hypothetical and real scenarios (e.g., Clot et al., 2018; Ferguson et al., 2019).

In the present study, there was an imbalance between male and female participants. This difference was caused by the difficulty to recruit the same number of male and female participants who met the very specific inclusion criteria. Nevertheless, it is known that gender can have an influence on forgiveness processes, as woman are known to show more forgiveness behavior than men (Shackelford et al., 2002; Wade and Goldman, 2006). For further investigation of the neural foundations of these differences in future studies, researchers should aim for a gender balance.

Another potentially critical point of the present study is the various approaches used to analyze the results of the behavior in the DG and the Emotional Stroop task and the neural activation differences between the groups. Due to the different research questions targeted in this study with different tasks and approaches it was not possible to limit the statistical analyses to one specific test. Therefore, keeping a potential power inflection in mind, the results have to be interpreted with some caution, even if the discussed results seem robust. Additionally, the Emotional Stroop task was used after the UG/DG, and due to this order, it was possible to investigate the emotional influence of the gaming paradigms on different participant groups. It is potentially critical that due to this order there was a systematical influence of the gaming paradigms on the results of the Emotional Stroop task.

In conclusion, the results of this study provide new insights into the impact of impulsivity on forgiveness behavior and the underlying mechanisms of cognitive control. First, behavioral data indicate a difference in the ability and/or willingness to forgive between low impulsivity vs. highly impulsive subjects. Second, regression analyses and the fNIRS data indicate that these differences in retaliation are possibly based on different motivations: while the behavior of the low impulsivity group could mainly be associated with sympathy, the behavior of highly impulsive subjects might have been determined by feelings of revenge. Keeping the fundamental importance of reconciliation for health (Friedberg et al., 2007), coping with stress (Worthington et al., 2007) and overall mortality (Toussaint et al., 2012) in mind, the data in this study provide relevant insights into mechanisms underlying reduced forgiveness behavior in highly-impulsive subjects, with possible clinical implications, for example, for patients with $\mathrm{ADHD}$, addiction or personality disorders.

\section{DATA AVAILABILITY STATEMENT}

The datasets generated for this study are available on request to the corresponding author.

\section{ETHICS STATEMENT}

This study was approved by the ethics committee of the Medical Faculty of the University of Tübingen and was in accordance with the current version of the Declaration of Helsinki. Written informed consent was obtained from all participants.

\section{AUTHOR CONTRIBUTIONS}

$\mathrm{MM}, \mathrm{A}-\mathrm{CE}, \mathrm{FH}$, and $\mathrm{MB}$ contributed to the conception and design of the study. MM ran the study and organized the data. $\mathrm{MM}, \mathrm{DR}$, and A-CE performed the statistical analysis. MM wrote the first draft of the manuscript. A-CE, DR, and $\mathrm{MB}$ wrote sections of the manuscript. All authors critically revised the manuscript for important intellectual content and read and approved the submitted version. 


\section{FUNDING}

This study was supported by the German Research Foundation [Deutsche Forschungsgemeinschaft (DFG) project number $\mathrm{EH}$ 388/2-1]. A-CE was partly supported by IZKF Tübingen (Junior Research Group, grant 2115-0-0). We acknowledge support from the Open Access Publishing Fund of the University of Tübingen.

\section{REFERENCES}

Allemand, M., Sassing-Meng, A., Huber, S., and Schmitt, M. (2008). Entwicklung und validierung einer skala der bereitschaft zu verzeihen. Diagnostica 54, 71-84. doi: 10.1026/0012-1924.54.2.71

Bari, A., and Robbins, T. W. (2013). Inhibition and impulsivity: behavioral and neural basis of response control. Prog. Neurobiol. 108, 44-79. doi: 10.1016/j. pneurobio.2013.06.005

Barth, B., Kroczek, A., Deppermann, S., Dresler, T., Fallgatter, A. J., and Ehlis, A.-C. (2015). Epidemiologie und pathogenese der komorbidität von aufmerksamkeitsdefizit-/hyperaktivitätsstörung (ADHS) und sucht-die rolle der exekutivfunktionen. SUCHT 61, 279-291. doi: 10.1024/0939-5911.a000384

Beck, A. T., Steer, R. A., and Brown, G. K. (1996). Beck depression inventory-II. San Antonio 78, 490-498.

Botvinick, M. M., Braver, T. S., Barch, D. M., Carter, C. S., and Cohen, J. D. (2001). Conflict monitoring and cognitive control. Psychol. Rev. 108, 624-652. doi: 10.1037/0033-295X.108.3.624

Brown, R. P. (2003). Measuring individual differences in the tendency to forgive: construct validity and links with depression. Pers. Soc. Psychol. Bull. 29, 759-771. doi: 10.1177/0146167203029006008

Brüne, M., Juckel, G., and Enzi, B. (2013). "An eye for an eye"? Neural correlates of retribution and forgiveness. PLoS One 8:e73519. doi: 10.1371/journal.pone. 0073519

Bush, G., Luu, P., and Posner, M. I. (2000). Cognitive and emotional influences in anterior cingulate cortex. Trends Cogn. Sci. 4, 215-222. doi: 10.1016/s13646613(00)01483-2

Clark, A. J. (2005). Forgiveness: a neurological model. Med. Hypotheses 65, 649-654. doi: 10.1016/j.mehy.2005.04.041

Clot, S., Grolleau, G., and Ibanez, L. (2018). Shall we pay all? An experimental test of Random Incentivized Systems. J. Behav. Exp. Econ. 73, 93-98. doi: 10.1016/j. socec.2018.01.004

Crockett, M. J., Clark, L., Lieberman, M. D., Tabibnia, G., and Robbins, T. W. (2010). Impulsive choice and altruistic punishment are correlated and increase in tandem with serotonin depletion. Emotion 10, 855-862. doi: 10.1037/a0019861

Cui, X., Bray, S., and Reiss, A. L. (2010). Functional near infrared spectroscopy (NIRS) signal improvement based on negative correlation between oxygenated and deoxygenated hemoglobin dynamics. Neuroimage 49, 3039-3046. doi: 10.1016/j.neuroimage.2009.11.050

Delorme, A., and Makeig, S. (2004). EEGLAB: an open source toolbox for analysis of single-trial EEG dynamics including independent component analysis. J. Neurosci. Methods 134, 9-21. doi: 10.1016/j.jneumeth.2003.10.009

Dunnett, C. W. (1955). A multiple comparison procedure for comparing several treatments with a control. J. Am. Stat. Assoc. 50, 1096-1121. doi: 10.1080/01621459.1955.10501294

Egner, T., and Hirsch, J. (2005). The neural correlates and functional integration of cognitive control in a Stroop task. Neuroimage 24, 539-547. doi: 10.1016/j. neuroimage.2004.09.007

Ehlis, A.-C., Bähne, C. G., Jacob, C. P., Herrmann, M. J., and Fallgatter, A. J. (2008). Reduced lateral prefrontal activation in adult patients with attentiondeficit/hyperactivity disorder (ADHD) during a working memory task: a functional near-infrared spectroscopy (fNIRS) study. J. Psychiatr. Res. 42, 1060-1067. doi: 10.1016/j.jpsychires.2007.11.011

Espín, A. M., Exadaktylos, F., Herrmann, B., and Brañas-Garza, P. (2015). Shortand long-run goals in ultimatum bargaining: impatience predicts spite-based behavior. Front. Behav. Neurosci. 9:214. doi: 10.3389/fnbeh.2015.00214

\section{ACKNOWLEDGMENTS}

We would like to thank Björn Enzi for sharing the presentation file. We would also like to thank Ramona Täglich, Alexander Krieg, Hendrik Laicher, and Julian Schiel for their valuable support with collecting the data, as well as Nora Güthlein for her great assistance with correcting the fNIRS data.

Fallgatter, A. J., Ehlis, A.-C., Rösler, M., Strik, W. K., Blocher, D., and Herrmann, M. J. (2005). Diminished prefrontal brain function in adults with psychopathology in childhood related to attention deficit hyperactivity disorder. Psychiatry Res. 138, 157-169. doi: 10.1016/j.pscychresns.2004. 12.002

Fallgatter, A., Ehlis, A. C., Wagener, A., Michel, T., and Herrmann, M. (2004). Nah-Infrarot-spektroskopie in der Psychiatrie. Der Nervenarzt 75, 911-916. doi: 10.1007/s00115-002-1457-2

Fehr, E., and Fischbacher, U. (2004). Third-party punishment and social norms. Evol. Hum. Behav. 25, 63-87. doi: 10.1016/s1090-5138(04) 00005-4

Ferguson, E., Zhao, K., O’Carroll, R. E., and Smillie, L. D. (2019). Costless and costly prosociality: correspondence among personality traits, economic preferences, and real-world prosociality. Soc. Psychol. Personal. Sci. 10, 461-471. doi: 10.1177/1948550618765071

Fincham, F. D., Hall, J., and Beach, S. R. (2006). Forgiveness in marriage: current status and future directions. Fam. Relat. 55, 415-427. doi: 10.1111/j.1741-3729. 2005.callf.x-i1

Friedberg, J. P., Suchday, S., and Shelov, D. V. (2007). The impact of forgiveness on cardiovascular reactivity and recovery. Int. J. Psychophysiol. 65, 87-94. doi: 10.1016/j.ijpsycho.2007.03.006

Gibbons, J. D., and Chakraborti, S. (2011). "Nonparametric statistical inference," in International Encyclopedia of Statistical Science, ed. M. Lovric (Heidelberg: Springer), 977-979.

Haeussinger, F. B., Heinzel, S., Hahn, T., Schecklmann, M., Ehlis, A.-C., and Fallgatter, A. J. (2011). Simulation of near-infrared light absorption considering individual head and prefrontal cortex anatomy: implications for optical neuroimaging. PLoS One 6:e26377. doi: 10.1371/journal.pone.0026377

Herrmann, M. J., Mader, K., Schreppel, T., Jacob, C., Heine, M., BoreattiHümmer, A., et al. (2010). Neural correlates of performance monitoring in adult patients with attention deficit hyperactivity disorder (ADHD). World J. Biol. Psychiatry 11, 457-464. doi: 10.1080/15622970902977552

Herrmann, M. J., Saathoff, C., Schreppel, T. J., Ehlis, A.-C., Scheuerpflug, P., Pauli, P., et al. (2009). The effect of ADHD symptoms on performance monitoring in a non-clinical population. Psychiatry Res. 169, 144-148. doi: $10.1016 /$ j.psychres.2008.06.015

Hirsch, J. K., Webb, J. R., and Jeglic, E. L. (2011). Forgiveness, depression, and suicidal behavior among a diverse sample of college students. J. Clin. Psychol. 67, 896-906. doi: 10.1002/jclp.20812

Huang, Y.-Z., Edwards, M. J., Rounis, E., Bhatia, K. P., and Rothwell, J. C. (2005). Theta burst stimulation of the human motor cortex. Neuron 45, 201-206. doi: 10.1016/j.neuron.2004.12.033

Inzlicht, M., Bartholow, B. D., and Hirsh, J. B. (2015). Emotional foundations of cognitive control. Trends Cogn. Sci. 19, 126-132. doi: 10.1016/j.tics.2015.01.004

James, L. M., and Taylor, J. (2007). Impulsivity and negative emotionality associated with substance use problems and Cluster B personality in college students. Addict. Behav. 32, 714-727. doi: 10.1016/j.addbeh.2006.06.012

Jasper, H. H. (1958). The ten-twenty electrode system of the International Federation. Electroencephalogr. Clin. Neurophysiol. 10, 370-375.

Jones, D. N., and Paulhus, D. L. (2011). The role of impulsivity in the Dark Triad of personality. Pers. Individ. Dif. 51, 679-682. doi: 10.1016/j.paid.2011.04.011

Karremans, J. C., and van der Wal, R. C. (2013). It takes more to forgive: The role of executive control. Behav Brain Sci. 36, 25. doi: 10.1017/S0140525X12000532

Kerns, J. G., Cohen, J. D., MacDonald, A. W. III., Cho, R. Y., Stenger, V. A., and Carter, C. S. (2004). Anterior cingulate conflict monitoring and adjustments in control. Science 303, 1023-1026. doi: 10.1126/science.1089910 
Kessler, R. C., Adler, L., Ames, M., Demler, O., Faraone, S., Hiripi, E., et al. (2005). The World Health Organization Adult ADHD Self-Report Scale (ASRS): a short screening scale for use in the general population. Psychol. Med. 35, 245-256. doi: 10.1017/s0033291704002892

Leiner, D. (2018). SoSci Survey Version 2.5. 00-i (Computer Software). 2014. Available online at: https://www.soscisurvey.de [Zugriff: 14.8. 2014] External link.

Maier, M. J., Rosenbaum, D., Haeussinger, F. B., Brüne, M., Enzi, B., Plewnia, C., et al. (2018). Forgiveness and cognitive control-Provoking revenge via thetaburst-stimulation of the DLPFC. Neuroimage 183, 769-775. doi: 10.1016/j. neuroimage.2018.08.065

Miyake, A., and Friedman, N. P. (2012). The nature and organization of individual differences in executive functions: four general conclusions. Curr. Dir. Psychol. Sci. 21, 8-14. doi: 10.1177/0963721411429458

Miyake, A., Friedman, N. P., Emerson, M. J., Witzki, A. H., Howerter, A., and Wager, T. D. (2000). The unity and diversity of executive functions and their contributions to complex "frontal lobe" tasks: a latent variable analysis. Cogn. Psychol. 41, 49-100. doi: 10.1006/cogp.1999.0734

Moffitt, T. E., Arseneault, L., Belsky, D., Dickson, N., Hancox, R. J., Harrington, H., et al. (2011). A gradient of childhood self-control predicts health, wealth, and public safety. Proc. Natl. Acad. Sci. U S A 108, 2693-2698. doi: 10.1073/pnas. 1010076108

Müller-Leinß, J. M., Enzi, B., Flasbeck, V., and Brüne, M. (2018). Retaliation or selfishness? An rTMS investigation of the role of the dorsolateral prefrontal cortex in prosocial motives. Soc. Neurosci. 13, 701-709. doi: 10.1080/17470919. 2017.1411828

Nota, L., Soresi, S., and Zimmerman, B. J. (2004). Self-regulation and academic achievement and resilience: a longitudinal study. Int. J. Educ. Res. 41, 198-215. doi: 10.1016/j.ijer.2005.07.001

Pingleton, J. P. (1989). The role and function of forgiveness in the psychotherapeutic process. J. Psychol. Theol. 17, 27-35. doi: 10.1177/ 009164718901700106

Plichta, M., Heinzel, S., Ehlis, A.-C., Pauli, P., and Fallgatter, A. (2007). Modelbased analysis of rapid event-related functional near-infrared spectroscopy (NIRS) data: a parametric validation study. Neuroimage 35, 625-634. doi: 10.1016/j.neuroimage.2006.11.028

Pronk, T. M., Karremans, J. C., Overbeek, G., Vermulst, A. A., and Wigboldus, D. H. (2010). What it takes to forgive: when and why executive functioning facilitates forgiveness. J. Pers. Soc. Psychol. 98, 119-131. doi: 10.1037/a0017875

Ricciardi, E., Rota, G., Sani, L., Gentili, C., Gaglianese, A., Guazzelli, M., et al. (2013). How the brain heals emotional wounds: the functional neuroanatomy of forgiveness. Front. Hum. Neurosci. 7:839. doi: 10.3389/fnhum.2013.00839

Rorden, C., and Brett, M. (2000). Stereotaxic display of brain lesions. Behav. Neurol. 12, 191-200. doi: 10.1155/2000/421719

Rosenbaum, D., Haipt, A., Fuhr, K., Haeussinger, F. B., Metzger, F. G., Nuerk, H.C., et al. (2017). Aberrant functional connectivity in depression as an index of state and trait rumination. Sci. Rep. 7:2174. doi: 10.1038/s41598-017-02277-z

Rosenbaum, D., Hilsendegen, P., Thomas, M., Haeussinger, F. B., Metzger, F. G., Nuerk, H.-C., et al. (2018a). Cortical hemodynamic changes during the Trier Social Stress Test: an fnirs study. Neuroimage 171, 107-115. doi: 10.1016/j. neuroimage.2017.12.061

Rosenbaum, D., Maier, M. J., Hudak, J., Metzger, F. G., Wells, A., Fallgatter, A. J., et al. (2018b). Neurophysiological correlates of the attention training technique: a component study. Neuroimage Clin. 19, 1018-1024. doi: 10.1016/j.nicl.2018. 06.021

Rosenbaum, D., Thomas, M., Hilsendegen, P., Metzger, F. G., Haeussinger, F. B., Nuerk, H.-C., et al. (2018c). Stress-related dysfunction of the right inferior frontal cortex in high ruminators: an fNIRS study. Neuroimage Clin. 18, 510-517. doi: 10.1016/j.nicl.2018.02.022

Sanfey, A. G., Rilling, J. K., Aronson, J. A., Nystrom, L. E., and Cohen, J. D. (2003). The neural basis of economic decision-making in the ultimatum game. Science 300, 1755-1758. doi: 10.1126/science.1082976

Shackelford, T. K., Buss, D. M., and Bennett, K. (2002). Forgiveness or breakup: sex differences in responses to a partner's infidelity. Cogn. Emot. 16, 299-307. doi: 10.1080/02699930143000202

Shamay-Tsoory, S. G., Aharon-Peretz, J., and Perry, D. (2009). Two systems for empathy: a double dissociation between emotional and cognitive empathy in inferior frontal gyrus versus ventromedial prefrontal lesions. Brain 132, 617-627. doi: 10.1093/brain/awn279

Sherman, L. E., Rudie, J. D., Pfeifer, J. H., Masten, C. L., McNealy, K., and Dapretto, M. (2014). Development of the default mode and central executive networks across early adolescence: a longitudinal study. Dev. Cogn. Neurosci. 10, 148-159. doi: 10.1016/j.dcn.2014.08.002

Singh, A. K., Okamoto, M., Dan, H., Jurcak, V., and Dan, I. (2005). Spatial registration of multichannel multi-subject fNIRS data to MNI space without MRI. Neuroimage 27, 842-851. doi: 10.1016/j.neuroimage.2005. 05.019

Smith, P., and Waterman, M. (2003). Processing bias for aggression words in forensic and nonforensic samples. Cogn. Emot. 17, 681-701. doi: 10.1080/02699930302281

Sridharan, D., Levitin, D. J., and Menon, V. (2008). A critical role for the right fronto-insular cortex in switching between central-executive and default-mode networks. Proc. Natl. Acad. Sci. U S A 105, 12569-12574. doi: 10.1073/pnas. 0800005105

Strobel, A., Zimmermann, J., Schmitz, A., Reuter, M., Lis, S., Windmann, S., et al. (2011). Beyond revenge: neural and genetic bases of altruistic punishment. Neuroimage 54, 671-680. doi: 10.1016/j.neuroimage.2010. 07.051

Toussaint, L. L., Owen, A. D., and Cheadle, A. (2012). Forgive to live: forgiveness, health, and longevity. J. Behav. Med. 35, 375-386. doi: 10.1007/s10865-0119362-4

Townsend, J. T., and Ashby, F. G. (1983). Stochastic Modeling of Elementary Psychological Processes. Cambridge, MA: CUP Archive.

Tse, M. C., and Cheng, S.-T. (2006). Depression reduces forgiveness selectively as a function of relationship closeness and transgression. Pers. Individ. Dif. 40, 1133-1141. doi: 10.1016/j.paid.2005.11.008

Tsuzuki, D., Jurcak, V., Singh, A. K., Okamoto, M., Watanabe, E., and Dan, I. (2007). Virtual spatial registration of stand-alone fNIRS data to MNI space. Neuroimage 34, 1506-1518. doi: 10.1016/j.neuroimage.2006. 10.043

Verdejo-Garcia, A. J., López-Torrecillas, F., Aguilar de Arcos, F., and PérezGarcia, M. (2005). Differential effects of MDMA, cocaine, and cannabis use severity on distinctive components of the executive functions in polysubstance users: a multiple regression analysis. Addict. Behav. 30, 89-101. doi: 10.1016/j. addbeh.2004.04.015

Wade, N. G., and Goldman, D. B. (2006). Sex, group composition, and the efficacy of group interventions to promote forgiveness. Group Dyn. 10, 297-308. doi: 10.1037/1089-2699.10.4.297

Watts, F. N., McKenna, F. P., Sharrock, R., and Trezise, L. (1986). Colour naming of phobia-related words. Br. J. Psychol. 77, 97-108. doi: 10.1111/j.2044-8295. 1986.tb01985.x

Wilkowski, B. M., Robinson, M. D., and Troop-Gordon, W. (2010). How does cognitive control reduce anger and aggression? The role of conflict monitoring and forgiveness processes. J. Pers. Soc. Psychol. 98, 830-840. doi: $10.1037 / \mathrm{a} 0018962$

Williams, J. M. G., Mathews, A., and MacLeod, C. (1996). The emotional Stroop task and psychopathology. Psychol. Bull. 120, 3-24. doi: 10.1037/0033-2909. 120.1 .3

Worthington, E. L. Jr., Witvliet, C. V. O., Pietrini, P., and Miller, A. J. (2007). Forgiveness, health and well-being: a review of evidence for emotional versus decisional forgiveness, dispositional forgivingness, and reduced unforgiveness. J. Behav. Med. 30, 291-302. doi: 10.1007/s10865-0079105-8

Conflict of Interest: The authors declare that the research was conducted in the absence of any commercial or financial relationships that could be construed as a potential conflict of interest.

Copyright (c) 2019 Maier, Rosenbaum, Haeussinger, Brüne, Fallgatter and Ehlis. This is an open-access article distributed under the terms of the Creative Commons Attribution License (CC BY). The use, distribution or reproduction in other forums is permitted, provided the original author(s) and the copyright owner(s) are credited and that the original publication in this journal is cited, in accordance with accepted academic practice. No use, distribution or reproduction is permitted which does not comply with these terms. 